May 2021

\title{
Central-Peripheral Information Behavior Theory
}

\section{Laura Maw}

San Jose State University, laura.maw@sjsu.edu

Follow this and additional works at: https://scholarworks.sjsu.edu/ischoolsrj

Part of the Library and Information Science Commons

\section{Recommended Citation}

Maw, L. (2021). Central-Peripheral Information Behavior Theory. School of Information Student Research Journal, 11(1). https://doi.org/10.31979/2575-2499.110105 Retrieved from https://scholarworks.sjsu.edu/ischoolsrj/vol11/iss1/5

This article is brought to you by the open access Journals at SJSU ScholarWorks. It has been accepted for inclusion in School of Information Student Research Journal by an authorized administrator of SJSU ScholarWorks. For more information, please contact scholarworks@sjsu.edu. 


\title{
Central-Peripheral Information Behavior Theory
}

\begin{abstract}
In researching information behavior theory, a significant gap has been revealed: How can information behavior theory comprehensively identify the information behaviors and needs of information communities without the foundational understanding of information, communication, and community, and their intersection? It is asserted in this paper that information behavior theory must clearly define information, communication and community, and how these terms intersect, to comprehensively identify information communities' information behaviors and needs. To test this thesis, a qualitative study on the tourist information community has been conducted. Seen through the lens of the novel central-peripheral information behavior (CPIB) theory, the tourist information community's central information behaviors are acquisitional (encountering, seeking, browsing, and searching) and emotional (reacting and sensing). The community's peripheral information behaviors are collaborating, sharing, and creating. Key information access needs are Internet and mobile technology. Prominent information use needs include mobile applications (e.g., Tripit), social media sites (e.g., Pinterest, and blog sites), Travel 2.0 websites (e.g., TripAdvisor), and e-commerce sites (e.g., Expedia). The paper's key findings about tourist information behaviors and needs can guide libraries in tailoring services to the tourist information community or hybrid (online and offline) information community member. Libraries have an opportunity to better serve the tourist information community by providing a trustworthy virtual space for members to get together through non-commercial travel cafes. Libraries are also uniquely positioned to help travelers become more culturally competent. In physical spaces of libraries, tourists can be attracted by offering strategically placed and spacious mobile device charging stations.
\end{abstract}

\section{Keywords}

central-peripheral information behavior theory, information behavior theory, tourist, traveler, information needs, information behaviors, information community

\section{About Author}

I have a Bachelor of Arts Honours Degree in Mass Communication with Minors in Psychology and Philosophy. I completed my undergraduate work at Carleton University in 2009. Since moving to British Columbia in 2011, I have worked for the Government of British Columbia.

Currently, I work full-time as a writer at the Ministry of Social Development and Poverty Reduction. As part of my job, I maintain a corporate messaging library containing hundreds of documents. I am also an author and have published two children's picture books, Bubba's Balloon and Ollie the Orca. In the future, I would like to work as a special librarian in a government library or as a public librarian in my community. I started San Jose State University's MLIS program in fall 2019 so I could work towards the qualifications needed for my career endeavors.

This article is available in School of Information Student Research Journal: https://scholarworks.sjsu.edu/ischoolsrj/ 
In the library and information science field, a common thread found in information behavior theory literature is the need to define the following fundamental terms: information, communication, community, and information community. Looking at the similarities and differences in how these concepts are defined and the subsequent information behavior theories that have emerged, it is clear that current information behavior theory lacks concise definitions of information, communication, and community as well as an understanding of how these terms intersect.

This problem sparked the following question: How can information behavior theory comprehensively identify the information behaviors and needs of information communities without the foundational understanding of information, communication, community, and their intersection? It is asserted in this paper that information behavior theory must clearly define the aforementioned terms to comprehensively identify information communities' information behaviors and needs. To test this thesis, a qualitative study consisting of a literature review on the tourist/traveler information community and an interview with a community member have been conducted.

To fill the current information behavior theory gap, the information, communication, and community (ICC) model and the central-peripheral information behavior (CPIB) theory have been created. In the ICC model, the foundational terms - information, communication, and community - and their intersection are clearly defined. To incorporate the ICC model into information behavior theory, the central-peripheral information behavior (CPIB) theory has been developed. Through the CPIB theory lens, the information needs and behaviors of the tourist information community have been comprehensively identified, bringing forward the opportunity for libraries and information centers to better serve this community.

\section{Information Behavior Core Concepts}

In reviewing information behavior literature, it was discovered that in the early to mid-1900s, Wiener's cybernetics theory stirred academic interest by examining information's relation to physical and social actions (Bates, 2009). Since then, there has been much attention paid to defining information. Bates (2009) identifies seven categories of information definitions, including communicatory/semiotic and social. The communicatory/semiotic and social definitions of information blend the meanings of information, communication, and community. In Bateson's communicatory/semiotic definition, information is seen as something that makes a difference to someone (Bates, 2009). Social definitions of information include Cornelius' human artefact of social situations and Goguen's interpretation of community signs (Bates, 2009).

In communication definitions, there is also cross-over with information and community. In Krikelas' information behavior model described by Case and Given (2016), the act of information giving can be interpreted as communication. Similarly, Biagi and McKie (1999) define communication as the transmission of feelings and thoughts between people or groups.

Definitions of community include reference to information and 
communication. A definition of community can be seen in Kuhlthau's (1991) description of her information search process model, where "evidence of the transmission of information into meaning is present in the products or presentations in which users share their new knowledge with others" (p. 361). Regarding the concept of community, Fisher and Bishop (2015) cite Hillary's core categories of community (geography, social interaction, and ties) and describe Christen and Levinson's four key angles of community (affinity, instrumental, primordial, and proximate). Fisher and Bishop (2015) define an information community as "a group of entities that blurs the boundaries between information seekers, users, and providers, recognizing that a single person or institution can embody multiple segments of the information life cycle" (p. 22). To strengthen their definition of an information community, Fisher and Bishop (2015) specify five characteristics of effective information communities. In summary, an effective information community has diverse information providers who collaborate to increase the community's capacity to meet their members' information access and use needs. This is accomplished by exploiting the information-sharing capabilities of technologies that increase social connectedness through barrier-free information sharing.

With respect to information behavior, much effort has been dedicated to looking at information acquisition behaviors. In her paper on information encountering, Erdelez (1999) focuses on describing information encountering as a distinct and valuable type of information acquisition behavior, separate from seeking and browsing. More generally, Bates (2017) summarizes information behavior as "the term used to describe the many ways in which human beings interact with information, in particular, the ways in which people seek and utilize information" (p. 2074). In Kuhlthau's (1991) information search process model, she identifies six stages - initiation, selection, exploration, formulation, collection, and presentation - where each stage is related to feelings that direct action.

\section{Method}

To review literature on the tourist information community, peer-reviewed journal articles were located using two common library information science databases: Library \& Information Science Source and Library and Information Science Collection. Community-based and research-based resources used by the tourist information community were also researched. To learn more about specific information resources used by tourists hiking the West Coast Trail, a tourist was interviewed about their travel information resources.

\section{Literature Review}

\section{Community Building Information Needs and Behaviors}

Dickinson et al. (2017) describe the tourist community's membership and connectivity building as a form of a "neighbourhood affect" (p. 175). Through their qualitative research study in which interviews were conducted with tourists and data was collected from their use of a collaborative travel application, they found that tourists form communities, including temporary communities, where 
people interact in physical spaces - and in these shared social spaces, temporary neighborhoods form. As such, it is necessary for tourist communities (subdivided by place) to maintain connections with members physically and virtually in order to increase capacity for community support within both temporary neighborhoods and established social networks. This research is important because it highlights how sociability is dependent on access to a technological tool (e.g., smartphone or laptop) and an Internet connection.

Community building also comes from tourists collaborating on information searching, which creates more of a shared experience for participants. With Mohammad Arif's and Du's (2019) research, they found that an effective (synchronous and asynchronous) collaborative information search system with user/group filters is needed to improve collaborative information searching and planning. To come to this conclusion, Mohammad Arif and Du conducted a mixed research study with the proposed design pilot (ColTIS) being assessed and compared to Google Talk-embedded Tripadvisor.com through the feedback of 18 pairs of participants.

\section{Information Access and Use Needs}

Through researching the information access and use needs of the tourist information community, key information access needs such as Internet and mobile technology were identified. Prominent information use needs were also identified, including social media/blog travel websites, Travel 2.0 websites, and e-commerce websites. In Magasic's (2014) auto-ethnographic qualitative research study, he conducted embedded research on travel blogging through writing a travel blog over the course of a three-month trip. Magasic found travel bloggers act as travel narrators who need to regularly find a place to access an Internet connection. As tourists find themselves using mobile devices while traveling, they too must regularly find an Internet connection to access the travel information they need.

Karanasios et al. (2015) found that mobile devices influence tourist information behavior. In their literature review, they analyzed the use of mobile devices throughout the three stages of travel planning (pre-trip, during-trip, and post-trip). Interestingly, they found that information access and consumption are occurring more in the during-trip stage because of mobile device technology. With the increased use of mobile devices during trips, there is an opportunity for tourists to explore local community services and attractions that may not be found during pre-trip Internet searches.

With the work of Tan et al. (2009), the changing information needs of tourists who use context-aware mobile device applications are examined. The researchers conducted a literature review to explore tourist information needs related to common travel tasks and context-aware mobile device applications. They also conducted two focus groups with eight participants in each. The researchers found that tourists use context-aware mobile device applications in five different contexts (temporal, identity, location, environmental, and social) to fulfill travel information needs. It is reasonable to expect that the use of context-aware mobile device applications will increase as the tourist information community's need for on-the-go information increases; future research should track this trend.

Tan and Goh (2015) looked at how tourists' social needs influence their use 
of collaborative information seeking mobile applications by conducting a diary study with 24 participants. They found that inter- and intragroup collaborative information seeking needs change based on context. Intergroup collaborative information seeking is more influential on tourist decision making than intragroup collaborative information seeking when looking to immediately use the information. Tourists experience social triggers in different social contexts, which promote collaborative information seeking with their intra- or intergroups. The importance of tourists understanding how to use online social network and contextaware mobile applications is underscored by their need to use social networks to identify potential collaborative information seekers during travel. Future research should investigate whether certain members of the tourist information community are getting left out as mobile technology advances.

Muñoz-Leiva et al. (2012) were interested in the impact that Travel 2.0 websites had on tourist behavior. To study this, they had 3,269 participants complete web questionnaires about three Travel 2.0 websites: a Tripadvisor community site on Hotel Botanico, Hotel Botanico's Facebook profile, and Hotel Botanico's blog. It was discovered that more tourists are using Travel 2.0 websites to meet their information needs because of the sites' perceived usefulness and ease of use, which creates site user trust. This study pairs nicely with the mobile device use findings of Karanasios et al. (2015); as more tourists access mobile technology to find information during their trips, local service and attraction Travel 2.0 websites will become increasingly relevant.

In Smith's (2004) literature review on how online travel marketplaces are changing tourist purchasing behavior, he found that as more tourists become Internet savvy, online travel marketplaces will continue to grow to meet tourist information needs. This is because online travel marketplaces increase consumer control through the integrated aspects of e-commerce, which increases the availability of discount travel. With the integrated aspects of e-commerce increasing the availability of travel discounts, it would seem logical that more people can afford to go on trips, thus increasing the size of the tourist information community and the need for travel information.

\section{Analysis}

\section{The Central-Peripheral Information Behavior Theory}

It is asserted in this paper that information behavior theory must clearly define information, communication, community, and how these terms intersect in order to comprehensively identify information communities' information behaviors and needs. Through examining information behavior theories and related definitions of information, communication, and community, as well as seeking to highlight the importance of the interdependency of these core concepts, the ICC model has been created. The model is simple in the sense that it only seeks to identify the definitions of these concepts in relation to the essence of their shared importance the message. In the ICC model, information is the substance of the message, communication is the transmission of the message, and community provides the meaning and evolution of the message. The interdependency of these concepts is represented in Figure 1. 
Figure 1

The ICC Model

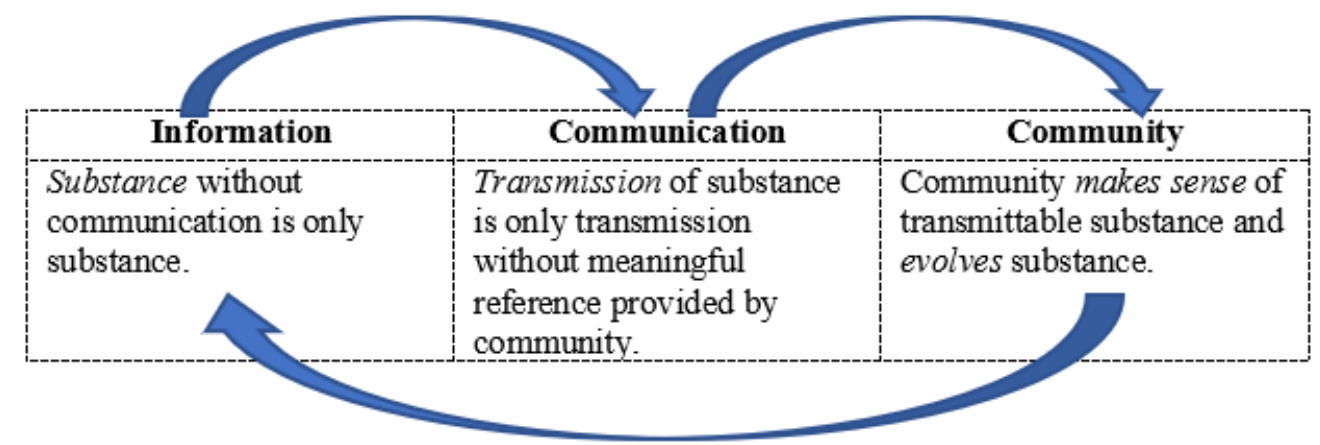

The CPIB theory has been developed to tie information behavior directly to the ICC model. The ICC model is at the core of the CPIB theory. With this strong foundation, the CPIB theory seeks to comprehensively identify information behaviors and needs. In the CPIB theory, there are two main types of information behaviors: central information behaviors (acquisitional and emotional) and peripheral information behaviors (collaborating, sharing, and creating). Acquisitional behaviors are encountering, seeking, browsing, and searching. Emotional behaviors are reacting and sensing. The peripheral information behaviors are interconnected. As people share what they create and collaborate on, more information is developed, which in turn spawns more ideas resulting in more creations and collaborations. Emotional behaviors are strictly visceral and contextual, whereas acquisitional behaviors and peripheral behaviors may be contextual or directed by information needs.

\section{The Tourist Information Community Example}

\section{Central Information Behaviors}

In terms of acquisitional behaviors (encountering, seeking, browsing, and searching), it has been found that the tourist information community primarily uses the Internet (Magasic, 2014) and mobile technology to satisfy their information needs in the context-based during-trip stage of planning, which is now the primary stage of planning for tourists (Karanasios et al., 2015). It has also been discovered that context, as identified by Tan et al. (2009), drives the emotional behaviors (reacting and sensing) of the tourist information community.

These findings are consistent with the information behaviors of other hybrid information communities. Based on the Horizon Reports from 2014 to 2019, mobile devices and applications, requiring Internet access, were of increasing importance to the post-secondary student information community. This is because, like with the tourist information community, "the pervasiveness of mobile devices is changing the way people interact with content and their surroundings" (The New Media Consortium, 2017, p. 40). Information communities are increasingly utilizing mobile applications to satisfy their communities' information needs. As mentioned in the 2014 Horizon Report, apps 
exist for almost everything people do (The New Media Consortium, 2014).

\section{Peripheral Information Behaviors}

In terms of peripheral information behaviors (collaborating, sharing, and creating), it has been found that these behaviors are effective in helping tourists fulfill their information needs. The interconnection of the peripheral information behaviors has also been demonstrated in this research. For example, it is the norm for tourists to collaborate on information searching through mobile applications for group trips (Mohammad Arif \& Du, 2019) and to share their experiences of travel with others through the creation of blog posts, which in turn, guide the readers' experiences (Magasic, 2014). Thus, peripheral information behaviors not only increase the amount of information available to the tourist information community through creation, they increase the social ties within the community through collaborating and sharing. This aligns with Hermida's (2014) conclusion about why people share information through social media:

Social media is transforming how we discover, learn and understand the world around us. But this is not a story about technology. People are not hooked on YouTube, Twitter or Facebook but on each other. Tools and services come and go; what is constant is our human urge to share. (Hermida, 2014, p. 1)

\section{Discussion}

\section{Library Programs and Services}

Two important information needs of the tourist information community include the need to access technology (e.g., Internet, computers, and mobile devices) and the need to learn how to use online social tools that help people maintain membership in the tourist information community. To assist tourists in maintaining membership in their community, libraries can help them meet their needs to access technology with an Internet connection and to learn how to use relevant applications or social media sites.

In Kenney's (2015) assessment of what library patrons wanted when visiting the White Plains Public Library, he found that many patrons were looking for help with technology use. As he states so pointedly,

And we've become the help desk for the community. It is assumed that libraries mostly help bridge the digital divide, assisting the poor and disenfranchised in getting online. But it's more complicated than that. Keeping up with the full range [of] technology today is a challenge for everyone, and when users have to fill in a knowledge gap, no matter their educational level or economic status, they're showing up at the reference desk. (Kenney, 2015, what patrons want section, para. 3)

Similarly, Lippincott (2015) found that there are promising opportunities to link technology-ready library spaces to learning.

Based on the White Plains Public Library's website (https://whiteplainslibrary.org/), patrons have access to many technologies and learning opportunities. The services most relevant to the tourist information 
community's information needs include social media 101 classes, WordPress web design classes, access to computers with Internet technology, tips on online shopping, and information about Sprint Wi-Fi hotspots. Even though this is an impressive list and representative of many other libraries' services, there are some services notably missing that would benefit the tourist information community and other hybrid information communities.

\section{Future Library Programs and Services}

It would benefit the tourist information community if members could access mobile devices with Internet technology that they could check out, not just tablets preloaded with learning applications for children (e.g., the Playaway Launchpad program at the White Plains Public Library). Library-hosted online cafés would also benefit the tourist information community by providing a virtual social space for members to connect, ask questions, provide advice, or discuss experiences. With a quick Google search for "online travel café," sites hosted by travel companies and agents were found, but nothing without a commercial agenda like what a library could offer. Additionally, mobile device charging stations could attract the tourist information community. These stations could be strategically placed near tourism reference books and posters advertising the library's online travel cafés. Through looking at many libraries' websites, it is evident that some libraries have begun providing charging stations for patrons.

\section{Libraries and Global Issues}

Studying the tourist information community has brought forward a social justice issue that has been examined in many different disciplines: the need for cultural competency learning. Companies are increasingly looking for these competencies when hiring employees, but the need to learn cultural competencies goes far beyond a requirement on a resume. As people become more globalized or internationally connected through technology, travel, social media, and global information communities, we must learn how to appreciate and embrace cultural differences to learn how to effectively work together to build a better world for everyone.

Magasic's (2014) findings about travel blog culture causing travel to become more of a standardized or homogenous experience raise concerns about the loss of opportunity to engage with local cultures more authentically and learn cultural competencies through experience. Libraries are uniquely positioned to fill this gap and support the growing need for these competencies in their communities by providing cultural competency learning opportunities. As always, "libraries are connecting ideas, information and people, and they are facilitating the development of new knowledge in their communities" (Holmquist, 2014, para. 11).

\section{Conclusion}

Through studying information behavior theory, it became clear that a more comprehensive approach was needed to understand the information behaviors and needs of information communities. A central question arose: How can information behavior theory comprehensively identify the information behaviors and needs of information communities without the foundational understanding of information, communication, and community, and their intersection? The ICC model and the 
CPIB theory have been created to fill this gap.

Information behavior theory must clearly define information, communication and community, and how these terms intersect, to comprehensively identify information communities' information behaviors and needs. With the CPIB theory and research on the tourist information community, it has been found that the tourist information community requires access to Internet and mobile technology to satisfy their travel information needs relevant to acquisitional behaviors (encountering, seeking, browsing, and searching). It has also been discovered that context drives the emotional behaviors (reacting and sensing) of the tourist information community. In terms of peripheral information behaviors, collaborating, sharing, and creating, it has been found that these interconnected behaviors are effective in helping tourists fulfill their information needs. Guided by the findings of this paper, libraries can improve services for the tourist information community by hosting virtual library cafés, providing access to cultural competency learning opportunities, and offering spacious mobile device charging stations within the physical space.

\section{References}

Bates, M. J. (2009). Information. In M. J. Bates \& M. Niles Maack (Eds.), Encyclopedia of library and information sciences (3rd ed., pp. 23472360). Taylor \& Francis Group. https://doi.org/10.1081/E-ELIS3120045519

Bates, M. J. (2017). Information behavior. In J. D. McDonald \& M. Levine-Clark (Eds.), Encyclopedia of library and information sciences (4th ed., pp. 2074- 2085). Taylor \& Francis Group. https://doi.org/10.1081/E-ELIS4

Biagi, S., \& McKie, C. (1999). Media impact: An introduction to mass media. Nelson Canada.

Case, D. O., \& Given, L. M. (2016). Models of information behavior. In J.-E. Mai (Ed.), Looking for information: A survey of research on information seeking, needs, and behavior (4th ed., pp. 141-175). Emerald Group Publishing.

Dickinson, J. E., Filimonau, V., Hibbert J. F., Cherrett, T., Davies, N., Norgate, S., Speed, C., \& Winstanley, C. (2017). Tourism communities and social ties: The role of online and offline tourist social networks in building social capital and sustainable practice. Journal of Sustainable Tourism, 25(2), 163- 180. https://doi.org/10.1080/09669582.2016.1182538

Erdelez, S. (1999). Information encountering: It's more than just bumping into information. Bulletin of the American Society for Information Science, 25(3), 25-29. https://doi.org/10.1002/bult.118

Fisher, K. E., \& Bishop, A. P. (2015). Information communities: Defining the focus of information service. In S. Hirsh (Ed.), Information services today: An introduction (2nd ed., pp. 20-26). Rowman \& Littlefield.

Hermida, A. (2014). Tell everyone: Why we share and why it matters. Doubleday Canada.

Holmquist, J. (2014, January 25). The library is the hummingbird. The Library Effect. http://thelibraryeffect.com/2014/01/25/the-library-is-the- 


\section{hummingbird/}

Karanasios, S., Sellitto, C., \& Burgess, S. (2015). Mobile devices and information patterns amongst tourists. Information Research, 20(1), 207210. http://informationr.net/ir/20-1/isic2/isicsp10.html\#.X68S7u5KiyI

Kenney, B. (2015). Where reference fits in the modern library. Publishers Weekly. https://www.publishersweekly.com/pw/by-topic/industrynews/libraries/article/68019-for-future-reference.html

Kuhlthau, C. C. (1991). Inside the search process: Information seeking from the user's perspective. Journal of the American Society for Information Science, 42(5), 361-371.

Lippincott, J. (2015). The future for teaching and learning. American Libraries. https://americanlibrariesmagazine.org/2015/02/26/the-future-forteaching- and-learning/

Magasic, M. (2014). Travel blogging: An auto-ethnographic study of how online interactions influence a journey. First Monday, 19(7). https://doi.org/10.5210/fm.v19i7.4887

Mohammad Arif, A. S., \& Du, J. T. (2019). Understanding collaborative tourism information searching to support online travel planning. Online Information Review, 43(3), 369-386. https://doi.org/10.1108/OIR-052017-0141

Muñoz-Leiva, F., Hernández-Méndez, J., \& Sánchez-Fernández, J. (2012). Generalising user behaviour in online travel sites through the Travel 2.0 website acceptance model. Online Information Review, 36(6), 879-902. https://doi.org/10.1108/14684521211287945

Smith, A. D. (2004). Information exchanges associated with Internet travel marketplaces. Online Information Review, 28(4), 292-300. https://doi.org/10.1108/14684520410553787

Tan, E. M.-Y., Foo, S., Goh, D. H.-L., \& Theng, Y.-L. (2009). TILES: Classifying contextual information for mobile tourism applications. Aslib Proceedings, 61(6), 565-586. https://doi.org/10.1108/00012530911005526

Tan, E. M.-Y., \& Goh, D. H.-L. (2015). A study of social interaction during mobile information seeking. Journal of the Association for Information Science \& Technology, 66(10), 2031-2044. https://doi.org/10.1002/asi.23310

The New Media Consortium. (2014). The NMC horizon report: 2014 library edition. https://library.educause.edu//media/files/library/2017/12/2014nmchorizonreportlibraryen.pdf

The New Media Consortium. (2017). The NMC horizon report: 2017 higher education edition. https://library.educause.edu//media/files/library/2017/2/2017horizonreporthe.pdf 